\title{
EMOTIONAL INTELLIIGENCE AMONG ALEXANDRIA UNIVERSITY DENTAL INTERNS
}

\author{
Esraa M Bishr' ${ }^{l} B D S$, Hala A Amer ${ }^{2} P h D$, Susan M Saleh² $P h D$
}

\begin{abstract}
INTRODUCTION: Emotional intelligence (EI) was reported to help in coping with stress, managing patients, improving doctor-patient relationship and trust; moreover, it leads to more successful career performance of dental students and professionals.

OBJECTIVES: To assess the EI levels of the dental interns according to socio-demographic and personal characteristics, and to some study related variables such as, reason for choosing dentistry, satisfaction with career choice and desire to enroll in a dental postgraduate sub-specialty program.

MATERIALS AND METHODS: The study was cross-sectional; it involved all Egyptian dental interns, graduated from the Faculty of Dentistry, Alexandria University, and enrolled in the internship program in the year of 2014-2015. Emotional Intelligence was assessed using the Genos, 31-item, self-reported, questionnaire, rated on a 5-point Likert scale, measuring EI across a seven subscale model and its relation to the different variables. All ethical and administrative approvals and permissions were obtained.

RESULTS: A total of 267 (157 females, 110 males) interns participated in the study, with response rate of $76.72 \%$. Most of the respondents $(84.3 \%)$ showed high EI, while $15.7 \%$ showed average EI, and none showed low EI. The highest scores were observed in 'emotional awareness of others' (mean $\%=71.2)$, and the least in 'emotional self-control' (mean $\%=64.5)$. Significantly higher EI $(\mathrm{p}<0.005)$ was detected in those who were males, single, chose dentistry as their own desire, were satisfied with choosing dentistry, and wanted to enroll in a postgraduate dental sub-specialty program. No significant differences were found regarding age, areas of residency, rate of internet use, type of parental education or job.

CONCLUSIONS: Fresh dental graduates from Alexandria Dental University have reported high overall EI levels, which were significantly associated with gender, marital status and study related variables, more studies are needed to find the role of EI in dental student's academic and clinical performance.
\end{abstract}

KEY WORDS: Emotional intelligence, EI competencies, dental education, dental students, communication skills.

1- Bachelor degree of oral and dental surgery, Faculty of dentistry, Alexandria University.

2- Professor of dental public health, Department of Pediatric Dentistry and Dental Public Health, Faculty of dentistry, Alexandria University.

\section{INTRODUCTION}

Emotional intelligence (EI) is the capacity for recognizing our own feelings and those of others, for motivating ourselves, and for managing our own emotions, as well as, our relationships with others (1). The term EI was first introduced in 1990, by Salovey and Mayer (2); who considered it as a pure cognitive ability. This was followed by the publications of the famous psychologist, Daniel Goleman (3), in 1995, who perceived EI as a mixed intelligence, involving cognitive ability and personality aspects. The author further reported that EI results in greater performance at work; whereas neither intelligence quotient (IQ), nor grades or examination scores, despite their popular use, could predict a person's success in life $(1,3)$.

Emotional intelligence is broader than social intelligence as it includes reasoning about the person's own internal emotions. It relates primarily to the emotional rather than verbal part of the personal and social problems (1). Furthermore, EI tests are not personality tests, because the personality traits rely on various skills and preferences, whereas, the ability to recognize a person's true feelings is considered as a mental ability. Therefore, it was reported that EI tests were developed to measure this particular construct and not other personality traits (4).

In 2006 Palmer (5) proposed a seven subscale model of $\mathrm{EI}$, together with its measuring scale named 'Genos', specifically designed to measure the typical EI performance in the workplace. The seven subscales are 'emotional selfawareness', 'emotional awareness of others' which are concerned with the recognition and understanding of feelings of self and others through behavioral cues. The 'emotional expression' implies communicating emotions, verbally or non-verbally, in the right way, at the right time and to the right people. The 'emotional reasoning' is about giving some consideration to emotions of self and others and incorporates them in the process of decision making or problem solving at work. The 'emotional self-management' and the 'emotional management of others' are concerned with regulating and modifying the emotions, continuously and skillfully, such as; the actions taken to motivate self or colleagues or helping self or others to resolve some issues that are causing distress, and finally the 'emotional selfcontrol' which is concerned with the controlling of intense emotions specifically; such as, anger or delight, with maintaining focus on the work in hand, unlike the emotional management it is considered more reactive than proactive, since the intense emotions are already evolved and their handling requires greater abilities to activate higher brain centers and avoid the drive of lower bran centers that are concerned with fear, fight and flight reactions. $(1,5,6)$

The role of EI in everyday life was explored by researchers who found that higher EI is related to better physical and psychological health, personal well-being, better communication skills and higher satisfaction with life $(3,6,7)$; on the other hand, lower EI was found to be related to maladaptive life style behaviors; such as, smoking, drug and alcohol use, unsafe sexual behaviors and aggressiveness $(6,8)$. EI brings new depth to the understanding and assessment of a person's general intelligence and provides important insights regarding what else is required for superior professional performance. In the work field; it was related to better stress coping, team working, leadership qualities, job satisfaction, less turnover intentions, less burnout and better overall performance $(1,6,9)$. 
In the medical field, previous research reported that doctors' EI positively correlated with their communication skills and patients' trust, which in turn correlated with better patient compliance, better doctor-patient relationships (10, $11,12)$ and increased satisfaction between the doctor, patient and hospital $(13,14)$. Moreover, it related to less perceived stress $(15,16,17)$, better stress coping strategies (18), and improved overall performance. The theory of EI is now being discussed within the education literature of health care; some studies explored its role in enhancing learning, academic performance and the overall quality of health care professionals. It explains some of the attributes which underlie the competencies that modern medical education seeks to deliver; such as the interpersonal and communication skills, and professionalism, this means that the EI abilities could be the building blocks that would allow students to develop these competencies in health care $(19,20)$. As a result, some researchers considered it as a new line of inquiry in the health professions, and a crucial component to medical education, and even suggested using it as one of the selection criteria before admission to medical schools. (6, 20-22).

Concerning the dental field; it was noticed that dentists who are able to recognize, regulate and direct emotions better, in themselves and in others; may be better equipped to handle stress, and promote social interactions at the work place. Moreover, the precision of history taking, diagnosis, and treatment planning is highly affected by the accuracy of assessing patients' emotions. Furthermore, dentists that can manage their patients' emotions and motivational factors effectively through tailored communications; can deal with patient's anxiety, gain their trust, and improve their abilities to cope with the disease and comply with the therapy. Therefore, dentists' EI is thought of as an important factor that positively influence the behavior at the workplace, and allow for better implementation of the other technical and business practice skills, as well as professionalism; hence, providing an empathetic, patient centered, quality health care $(11-13,15,16,18,23-25)$.

In 2009, Hannah et al. (11) conducted a cross-sectional study in New Zealand, on 116 third-year dental undergraduates during a course of 'consultation skills'. The results revealed that students who showed higher emotional and social skills demonstrated better interview performance, specifically in clarity of communication, thoroughness of information gathering, higher patients' satisfaction and compliance; moreover, they obtained significantly higher total performance scores.

In 2013, the dental school at Case Western Reserve University, USA, was among the first dental schools to examine the role of EI with regard to the dental students' clinical performance. Victoroff and Boyatzis (23) conducted the study on 3rd and 4th year dental students, using the emotional competence inventory-University version (ECI-U), and their overall clinical performance was assessed using the mean grade. Results showed a significant correlation between the EI dimension of "self-management skills" and the students' mean clinical grades. It was concluded that EI may be an important predictor of clinical performance, which has important implications for students' development during dental school.

Two descriptive cross-sectional studies similarly measured the EI in dental universities in India, using selfreported questionnaires that were rated on five point Likert scale. The first was conducted in 2013, by Bhaskar et al. (24) who studied 240 post-graduate students of Pedodontics and Preventive Dentistry specialties, aged 24-34 years, and found high overall EI scores among respondents. The study mentioned that an emotionally intelligent pediatric dentist might be able to introduce positive attitude towards oral health in childhood during the dental visits. The second study, on the other hand, was carried out in 2015, by Ravichandra et al. (25) who explored the EI of 186 dental undergraduate students and interns, aged 19-25, and reported lower overall EI scores.

In Egypt, no previous studies have been conducted within the medical or dental communities; however, two crosssectional studies measured student's EI at the faculties of Nursing, using self-reported questionnaires. In 2013, Mahmoud et al. (26) reported moderate EI scores in Alexandria University, after surveying a sample of 450 undergraduate nursing students across the four years of study, with mean age of 20.03. In 2016, Ibrahim et al. (27), explored the EI levels of 80 interns at the Faculty of Nursing, Ain Shams University; and revealed a high EI level among the majority of nursing interns.

Despite the acknowledged importance of EI, little work has explored the construct within the community of dentistry. Therefore, the current study aimed to discover the EI levels of the dental interns at Alexandria University according to their socio-demographic and personal characteristics, namely, gender, age, marital status, area of residency, type of high school, rate of internet use, parents' education and career. Moreover, it aimed to discover differences in EI levels according to some study related data, such as, reason for choosing dentistry, satisfaction with career choice and desire to enroll in a post-graduate dental sub-specialty program.

\section{MATERIALS AND METHODS:}

A cross sectional study was conducted. A comprehensive sample included all the available dental interns attending their internship training in the year 2014-2015, who were Egyptians, graduated from Alexandria University, their age did not exceed 25 years old. The study focused on the dental interns, who are fresh graduates; to reflect the EI levels after all the necessary education is finished and before being exposed to the work environment that might alter their learned experiences during college.

All ethical and administrative approvals were obtained from the faculty, as well as, the Alexandria Directorate of Health Affairs, in order to access the clinics. Moreover, permission of the interns to participate in the study was obtained after detailed explanation of the objectives of the research, confidentiality of data, and their right to accept or refuse participation was assured.

A pilot study was held by the researcher before the actual study, where twenty dental interns from the outpatient clinics, at the Faculty of Dentistry, responded to the questionnaire then the same twenty participants answered the same questionnaire again after two weeks. All the questionnaires were collected immediately by the researcher, no drop outs were detected, and then all the statistical analysis was done as appropriate. The scale showed acceptable validity and reliability of all its items, convergent validity of all subscales ranged from (0.45$0.76)$, and of each item in subscale ranged from (0.44-0.8), while test retest stability was $(0.78, \mathrm{p}<0.001)$, Cronbach's 
alpha $(\alpha=0.81)$; hence the questionnaire was acceptable for further use.

The actual study took place during a period of six months, from March to September 2015, at the Faculty of Dentistry, Alexandria University and at the Ministry of Health (MOH) facilities, namely: Elramad, Sharq Elmadina, Wingat, Ras-Eltin hospitals and Dental research center in Smouha. These places were reached several times to ensure participation of as many interns as possible.

The study instrument used was a self-reported, closedended questionnaire, written in English; and divided into two sections, the first comprised questions about sociodemographic, personal and study related data, while the second part contains the Genos EI self-assessment, concise version (28). The questionnaire was composed of 31 questions, and scored on a five-point Likert scale, from 'Almost Never' to 'Almost Always'. It investigates the typical EI performance at the work environment across seven subscales model of Parker et al. (5). Twelve questions in the scale were in the negative form, which means that if answered by 'Almost Never' would give the highest rating, their scores were reverse coded before the statistical analysis, by converting, code 1 to 5,2 to 4 , and vice versa (28). Each one of the seven subscales is measured by either 4 or 5 questions. The total score of each subscale is calculated by adding the individual values of its questions. For example, Emotional self-awareness is measured by 4 questions, therefore, its score range from 4 (if all answers were 'almost never') to 20 (if all answers were 'almost always'), on the other hand, the subscale of Emotional Expression is measured by 5 questions, therefore, its score range from 5 to 25 . Thus, the total EI score is calculated through the addition of all score values from the 31 questions and it ranges from 31 to 155 . For the reason that each subscale is composed of a different number of questions; therefore, the Mean Score Percent for each subscale was calculated in order to allow for a more meaningful comparison between them.

The collected data were revised and coded, then fed to and analyzed by the Statistical Package for Scientific Studies (SPSS 20.0, SPSS, Inc., Chicago, IL, USA.) for Windows. The developed graphs and charts were constructed using Microsoft excel software. The statistical significance was set at the $5 \%$ level $(\mathrm{p} \leq 0.05)$. Descriptive statistics were presented as frequencies (n) and percentages (\%). The relations between total EI scores and all the independent variables were analyzed using independent samples t-test and One-way ANOVA. The participants were distributed into three EI categories; according to the cut off levels of the percentile scores, as provided by the Genos original scale, however a merging of the High and very high categories was made, as well as the low and very low categories, to allow for better interpretation of the results. (High: 61\% - 99\%, Average: 41\% - 60\%, and Low: $1 \%$ $40 \%)$.

There were some difficulties faced by the researchers while choosing the appropriate tool for the study, since there are large numbers of EI tools, however, none of them was specifically designed for use in the dental educational settings, most of them were long, expensive, and required specific regulations for use. The Genos was chosen because it is specifically designed for use at the workplace settings. The scale is originally composed of two parts, a 'selfassessment' that is answered by the participant and a 'rater- assessment' answered by other persons who can rate the participants such as peers or supervisors. This study only used the 'self-assessment' part, due to some constrains, such as, the regular shift of internship places which doesn't allow the supervisors to know all the interns or get an accurate impression about them.

\section{RESULTS:}

A number of 348 interns were eligible for the study. The total number of interns that responded to the questionnaire was 267 (157 Females, 110 Males) with a response rate of $76.72 \%$.

Table (1) shows the distribution of the study participants $(n=267)$ according to the different socio-demographic, personal and study related characteristics. It was observed that more than half of the study participants were females $(58,8 \%)$, most of them were aged $23-25$ years $(73.7 \%)$, single $(88 \%)$, and residents of urban areas $(86.1 \%)$, more than half of them graduated in public high schools $(55.4 \%)$, reported using the internet regularly $(56.6 \%)$. Most of the participants' fathers and mothers had a university degree $(92.1 \%, 87.6 \%)$, respectively. Meanwhile, those who had none of their parents working at the medical field accounted for $78.7 \%$. Regarding their dental study related data, it was found that more than half of the participants reported to have chosen dentistry as their own desire (54.7\%), most of them reported satisfaction with studying dentistry (92.5\%), and the highest proportion wanted to enroll in a postgraduate dental sub-specialty program $(76 \%)$.

Table 1: Distribution of the study participants according to their Socio-demographic, personal characteristics, and study related variables.

\begin{tabular}{|c|c|c|c|}
\hline & Variables & $N(267)$ & $\%$ \\
\hline \multirow{2}{*}{ Gender } & Female & 157 & 58.8 \\
\hline & Male & 110 & 41.2 \\
\hline \multirow{2}{*}{ Age } & $20-22$ & 70 & 26.2 \\
\hline & $23-25$ & 197 & 73.7 \\
\hline \multirow{2}{*}{ Marital status } & Single & 235 & 88 \\
\hline & Married & 32 & 12 \\
\hline \multirow{2}{*}{ Area of residency } & Rural & 37 & 13.9 \\
\hline & Urban & 230 & 86.1 \\
\hline \multirow{2}{*}{ High school } & public & 148 & 55.4 \\
\hline & private & 119 & 44.6 \\
\hline \multirow{4}{*}{ Using the internet } & Sometimes & 21 & 7.9 \\
\hline & Often & 42 & 15.7 \\
\hline & Regularly & 151 & 56.6 \\
\hline & Addicted & 53 & 19.9 \\
\hline \multirow{3}{*}{ Fathers' Education } & Illiterate/ read \& write'/ementary & 6 & 23 \\
\hline & Secondary School & 15 & 5.6 \\
\hline & University & 246 & 92.1 \\
\hline \multirow{3}{*}{ Mothers' Education } & Illiterate/ read \& write elementary & 11 & 4.1 \\
\hline & Secondary School & 22 & 82 \\
\hline & University & 236 & 87.6 \\
\hline \multirow{2}{*}{ Parents Occupation } & Medical & 57 & 21.3 \\
\hline & Other & 210 & 78.7 \\
\hline \multirow{4}{*}{$\begin{array}{l}\text { Reason for studying } \\
\text { dentistry }\end{array}$} & \begin{tabular}{|l|l} 
Parents desire \\
\end{tabular} & 42 & 15.7 \\
\hline & Alternative to medicine & 60 & 22.5 \\
\hline & My own desire & 146 & 54.7 \\
\hline & Other & 19 & 7.1 \\
\hline \multirow{2}{*}{$\begin{array}{l}\text { Satisfaction with } \\
\text { studying dentistry }\end{array}$} & Satisfied & 247 & 92.5 \\
\hline & Not satisfied & 20 & 7.5 \\
\hline \multirow{3}{*}{ Desired sub-specialty } & Looking for a sub-specialize & 203 & 76 \\
\hline & Haven't decided yet & 45 & 16.9 \\
\hline & Not looking for subspecialty & 19 & 7.1 \\
\hline
\end{tabular}


Table (2) shows the minimum and maximum scores for each subscale, as well as, for total scores to represent the reported range. The mean and standard deviation are also calculated for each subscale and for the total EI. It was found that the reported range for the total EI scores was (76 - 137) and the mean score of the total EI was $104.9 \pm 11.6$ and its mean percent was $67.7 \% \pm 7.5$. Participants had the highest scores in Emotional Awareness of others (71.2\% $\pm 10.9)$ and the least in Emotional Self Control $(64.5 \%$ $\pm 12.6)$ and Emotional Expression $(64.5 \% \pm 9.8)$.

Figure 1 shows that most of the participants were observed in the high EI category (84.3\%), while (15.7\%) were in the average EI category and none were in the low. Concerning the subscales, similar results were found; the majority of the participants were observed in the high level category for each EI subscale, the highest observation was in the Emotional awareness of others $(80.9 \%)$, and the lowest was in Emotional self-control (57.7\%).

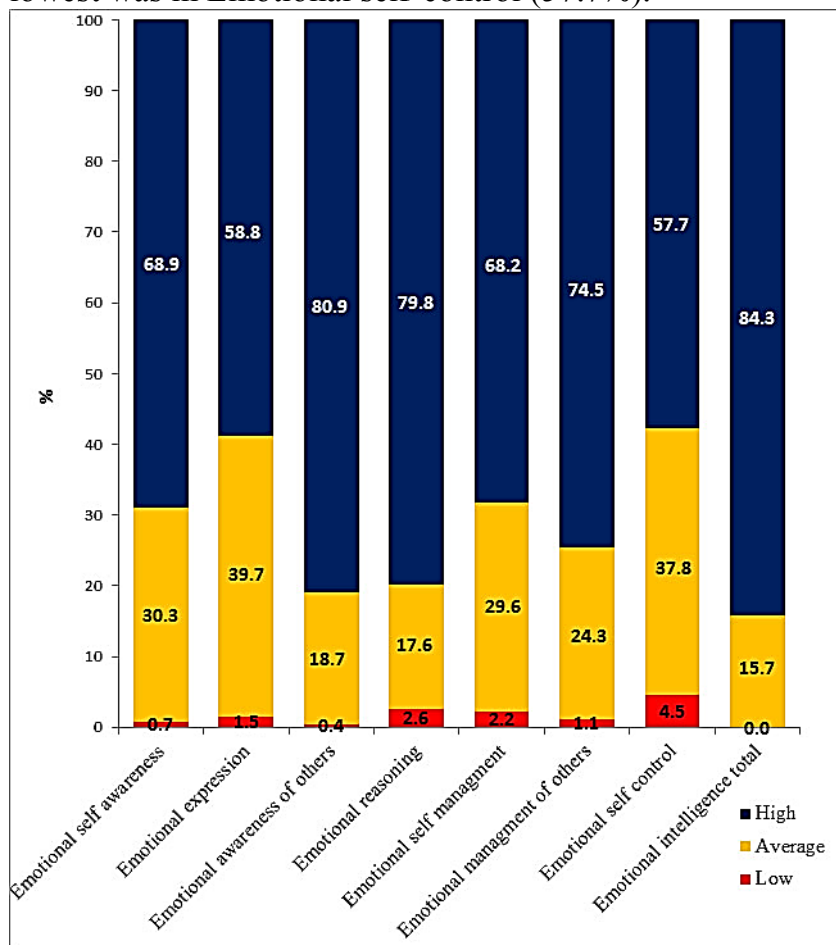

Figure 1: The distribution of study participants according to EI categories in the different subscales.

Figure 2 illustrates the total EI scores according to gender. Males showed higher EI levels $(106.9 \pm 12.6)$ than females $(103.5 \pm 10.7)$, with a significant difference $(\mathrm{t}=2.4$, $\mathrm{p}=0.016$ ).

Figure 3 shows the total EI scores according to the marital status. Single interns showed higher EI (105.4 \pm 11.9$)$ than the married ones $(101 \pm 8.4)$ with a significant difference $(t=2, p=0.045)$.

Figure 4 shows that, participants who chose dentistry as their own desire showed the highest EI scores (107.1 \pm 11.6$)$, followed by those who studied dentistry as an alternative to studying medicine which showed slightly higher EI than those that chose dentistry for other different reasons (104.5 $\pm 11.3,103.2 \pm 11.7$ ), respectively, and finally the group who studied dentistry as their parents' desire had lower EI (98.5 $\pm 9.5)^{~ d}$; with statistically significant difference ( $\mathrm{F}=6.7$ $\mathrm{p}=0.001$ ), accounted for by the last group in the post hock test.

Figure 5 revealed that participants who reported satisfaction with studying dentistry had higher EI scores (105.8 \pm 11.2$)$ than those who were not satisfied
(94.1 \pm 10.8$)$; with a statistically significant difference $(\mathrm{t}=4.5, \mathrm{p}=0.001)$.

Figure 6 illustrates that participants who wanted to take a sub-specialty, and those who have not decided yet, showed nearly equivalent levels of EI scores (105.3 \pm 11.6 , $105.8 \pm 11.1)$ respectively, while, those who don't want to take a sub-specialty showed much lower EI scores $(98.4$ $\pm 11.7)^{\mathrm{d}}$ with a statistically significant difference $(\mathrm{F}=3.3$, $\mathrm{p}=0.037$ ), accounted for by the last group in the post hock test.

No significant difference was found between participant's total EI scores regarding their age, area of residency, type of high school, rate of internet use, parent's education, or parent's job.

\section{DISCUSSION:}

This survey is the first in Egypt that aimed to assess the EI levels within a dental community. The study involved dental interns of the year 2014-2015 at the Faculty of Dentistry, Alexandria University and used the Genos selfreported EI questionnaire; it explored whether sociodemographic, personal and study related variables were associated with EI levels. The key findings are that the majority of participants showed high overall EI level, their highest scores were in emotional awareness of others and emotional management of others, while their least scores were in emotional self-control and emotional expression. A significant difference was found in favor of males and singles, in addition to participants who chose dentistry as their own desire, who reported satisfaction with studying dentistry and who wish to enroll in a post-graduate dental sub-specialty program.

The response rate in this study was adequate (76.72\%) providing strength and validity to results. The higher proportion of female to male respondents (Table 1) was consistent with the original gender distribution in the whole study population. The majority of dental interns showed high EI scores. This reflects that the dental fresh graduates of Alexandria University, generally, are expected to demonstrate good soft skills and subsequently become more successful practitioners $(1,6)$. It cannot be concluded from the results of this study, whether the participants already had high EI levels before admission to the faculty or if it was raised during their years of study, but it can be concluded that they graduated possessing high EI levels, further longitudinal studies are needed to investigate this relation.

Regarding other faculties of dentistry, these results were very close to those reported for dental post graduate students in India, where $58 \%$ and $19 \%$ of the respondents showed high and very high EI scores respectively, while none showed poor or very poor scores (24). However, the dental undergraduates and interns in India showed lower EI, as only $11.55 \%$ of the students showed high EI levels, 54\% showed average EI, while $28.8 \%$ and $2 \%$ showed poor and very poor EI, respectively (25). Furthermore, third-year dental undergraduates in New Zealand, also reported lower EI levels than those reported in the current study, since only $12.1 \%$ of the students showed high EI scores, while $72.45 \%$ and $15.5 \%$ showed average and low EI levels, respectively (11). This could be due to the variability of instruments used across these studies; however, a hypothesis can be raised that EI of the dental students increase gradually during their years of studying, and they graduate possessing the highest levels compared to undergraduates, when 
observed across different countries, This might be related to the fact that they deal with patients in their undergraduate clinical years of study, which could have enhanced their emotional awareness and management skills to handle the patients in those demanding situations.

In Egypt, the present results were higher than those reported among the nursing interns, at Ain-shams University; although the greater percentage of nursing interns $(65 \%)$ showed high EI levels, but $25 \%$ of the participants had low EI levels (27). Moreover, these results were also higher than those reported for undergraduate nursing students at the faculty of nursing, Alexandria University, since the greater percentages of nursing students, across the four years, ranging between $86.4 \%$ to $92 \%$, showed moderate EI levels (26). Once more, the results from these two studies might suggest that interns and graduates show higher EI levels than undergraduates, and EI could increase with age and study experience. Nevertheless, further studies are needed to confirm such relation. Though different measuring instruments were used to assess EI, but they were all self-reported questionnaires. Therefore it might be suggested that dental interns in the current study showed better EI skills than the nursing interns (27), and this might relate to several factors, such as, the fact that the faculty of dentistry only admits excellent students who achieved very high grades in high school, and that could reflect a higher EI level in that homogenous group originally, this is supported by the meta-analytic review of Perera and DiGacomo who found that EI could be considered as a predictor of academic performance across different study groups. (29) Besides it could be suggested that the nature of dental study allowed them to demonstrate emotionally intelligent behaviors, in order to deal with academic and clinical stressors.

The dental interns in the current study showed highest scores in "emotional awareness of others" (EAO) and "emotional management of others" (EMO) (Table 2 and Fig 1). These results could help in enhancing the degree of student's empathy and assist them to expand their communication skills at work. It is noted that these two subscales construct the social skills branch of a person's whole EI (1). A recent study in 2016, in Alexandria University, by Atteya et al. (30), reported that dental interns showed positive attitudes towards learning communication skills, it was also noticed that students have been learning communication skills through lectures incorporated into their dental public health curriculum; this could have taught them how to manage people's emotions through effective communications. Moreover, during the clinical years of study, participants might have experienced handling patients who were anxious or in pain, and this could have enhanced their awareness of people's emotions in addition to managing them at such emotionally stressful situation.

On the other hand, although the majority of dental interns reported high emotional self-control (ESC), however, this subscale showed the least scores when compared to all the other subscales (Table 2, Fig 1). This means that when experiencing these intense emotions, some of the participants are in high control of their behaviors and remain focused using their higher thinking brain centers, while others lose control over their reactions and become distracted, they apparently become driven by their lower brain centers and react in the same manner of fear, fight, and flight by shutting down their higher thinking brain centers
$(1,5,6)$. The reason for that might be related to age and experience, or this might relate to variability in participant's cognitive ability when performing under stressful conditions $(2,3)$. The "emotional expression" also showed lower scores than the other EI subscales (Fig 1). This could be related to some cultural context; since there are many misconceptions regarding expression of emotions and it is usually met by lots of criticism.

Table 2: Range of scores, mean, SD and mean $\%$ for all the EI subscales of the study participants.

\begin{tabular}{|c|c|c|c|c|c|c|c|}
\hline \multirow[t]{2}{*}{ EI } & \multirow{2}{*}{$\begin{array}{c}\text { Range of } \\
\text { scale }\end{array}$} & \multicolumn{2}{|c|}{$\begin{array}{l}\text { Reported } \\
\text { Range }\end{array}$} & \multirow{2}{*}{\multicolumn{2}{|c|}{$\begin{array}{c}\text { Mean } \\
\text { SD }\end{array}$}} & \multirow{2}{*}{\multicolumn{2}{|c|}{$\begin{array}{c}\text { Mean\% } \\
\text { SD }\end{array}$}} \\
\hline & & Min & Max & & & & \\
\hline Emotional Self Awar eness & $4-20$ & 7 & 20 & 13.8 & 2.3 & 68.8 & 11.7 \\
\hline Emotional Expression & $5-25$ & 8 & 24 & 16.1 & 2.4 & 64.5 & 9.8 \\
\hline Emotional Awareness of others & $4-20$ & 8 & 20 & 14.2 & 2.2 & 71.2 & 10.9 \\
\hline Emotional Reasoning & $5-25$ & 7 & 25 & 17.5 & 2.8 & 69.8 & 11.3 \\
\hline Emotional Self-Management & $5-25$ & 7 & 25 & 16.5 & 2.6 & 65.9 & 10.3 \\
\hline Emotional Management of others & $4-20$ & 7 & 19 & 14.0 & 2.2 & 69.8 & 10.9 \\
\hline Emotional Self-control & $4-20$ & 4 & 20 & 12.9 & 2.5 & 64.5 & 12.6 \\
\hline Total Emotional intelligence & $31-155$ & 76 & 137 & 104.9 & 11.6 & 67.7 & 7.5 \\
\hline
\end{tabular}

Regarding the gender differences in participants' total EI, the male respondents reported higher levels than the females, with statistically significant difference (Table 2, Fig 2). Females are typically considered to be superior to males in recognizing other people's emotions, having greater empathy and abilities as regards certain interpersonal skills (20). However, the female participants' EI scores in the current study were significantly lower than males. This may highlight that the association between gender and EI is not straight forward; it may depend on sociocultural factors in the community in which it is measured $(1,6,14)$. In our country, the males have more experience and control over their reactions, due to their familiarity with many outdoors interactions, in addition, females showing empathy with others and opening channels of communication with people could be misunderstood and therefore they may be more conservative in these aspects than males.

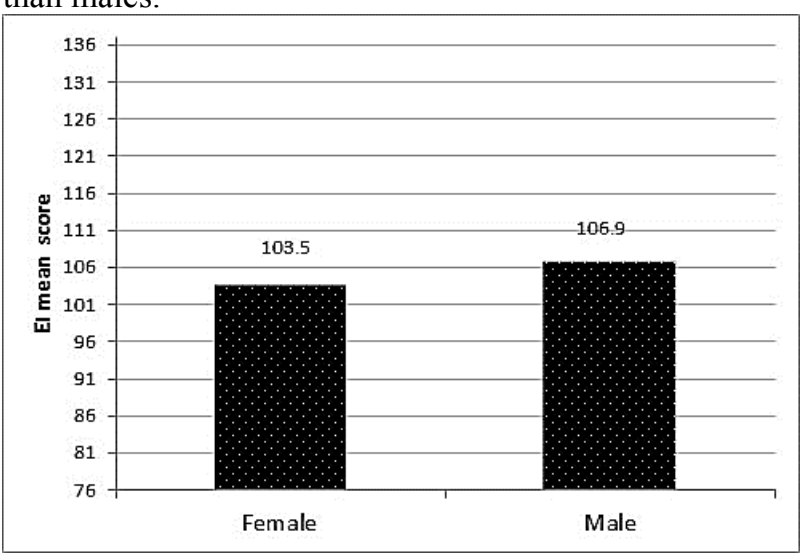

Figure 2: Total EI mean scores according to gender.

These gender differences found are in agreement with those reported among dental students in Iran (13), and India (24); while they were in contrary to the results of dental 
students reported in UK (15), New Zealand (11), and Japan (12), as well as, the medical students in UK (31), and USA (32). However, other studies in health care did not find any significant difference in EI between males and females (14, $16,17)$. This may provide evidence of the various cultural differences between communities, where female dentists have a greater opportunity to express their feelings or act with a degree of freedom with their patients in developed than developing countries.

With regard to the marital status; the majority of participants were single (Table 1) and they showed significantly higher EI levels than the married ones (Fig 3). The reason for this should be that the married interns are most probably recently married and experiencing a new stage in their lives, therefore, they might be affected by different stressors and new emotional experiences that have an impact on their EI and behavior at the mean time. Similar results were reported among the nursing interns in Cairo (27). However; other studies did not find any significant differences in regard to the marital status $(13,14)$.

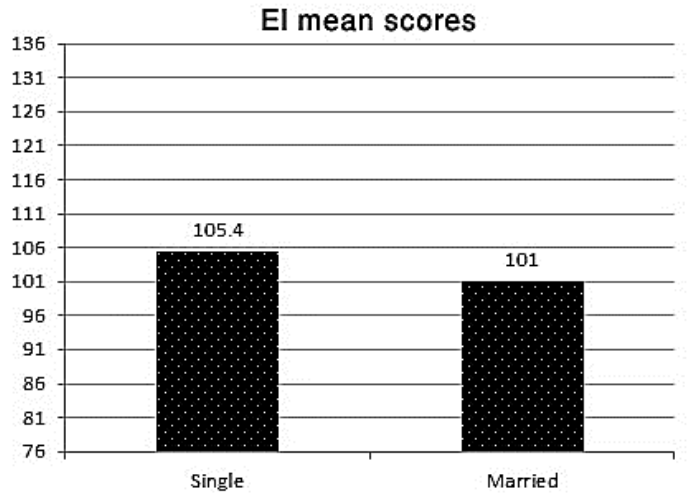

Figure 3: Total EI mean scores according to marital status

Looking at the reason for choosing to study dentistry; more than half of the respondents, reported that it was their own desire (Table 1), these respondents showed the highest EI levels. On the other hand, those who chose dentistry as their parent's desire, showed the least EI level, with a significant difference (Fig 4). The reason might be that those who chose to study dentistry or medicine have entered the profession out of a sense of compassion for reducing the suffering of others and the desire of helping them, hence they already had good levels of empathy and emotional understanding of others. In addition, they entered a profession they desired, therefore, they had the motivation to work on themselves and improve their skills, giving all their efforts to succeed (33). Moreover, students who do not enter the profession they desire, experience higher levels of stress during studying and this would accordingly affect their overall behavior (34).

When asked if they were satisfied or not with their choice to study dentistry; the majority of interns expressed satisfaction (Table 1) showing a significant difference in EI (Fig 5). This might be due to the effect of some intermediate factors, such as perceived stress (PS). It was reported that, when EI increases, PS decreases and vice versa. Low EI was even found as a significant predictor of PS, and students who were not satisfied by their career choice reported higher levels of PS $(16,17)$. The current results were supported by those of Pau et al. (16), in the multinational survey across seven countries, where the $76.7 \%$ of dental undergraduate students reporting satisfaction with decision to study dentistry, showed significantly higher EI levels (mean=125.4) than those who were not satisfied (mean= 118.7).

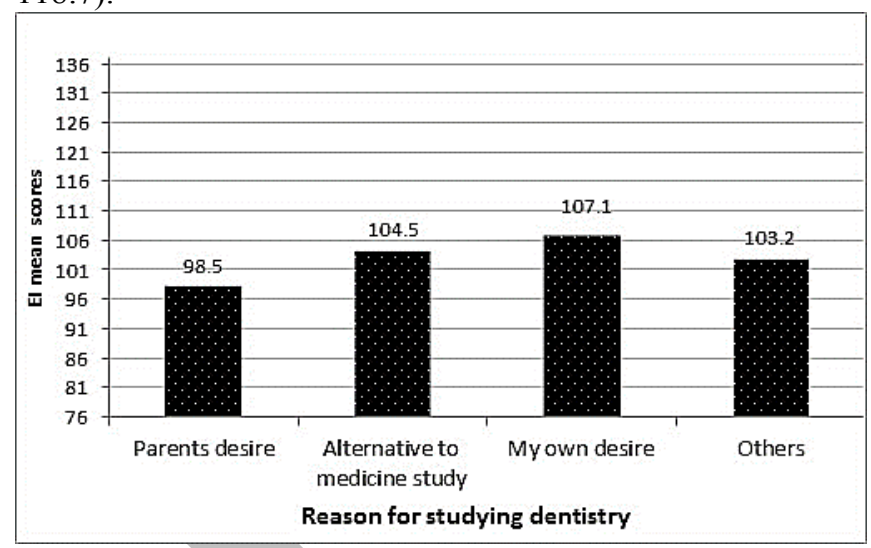

Figure 4: Total EI mean scores according to reason for studying dentistry.

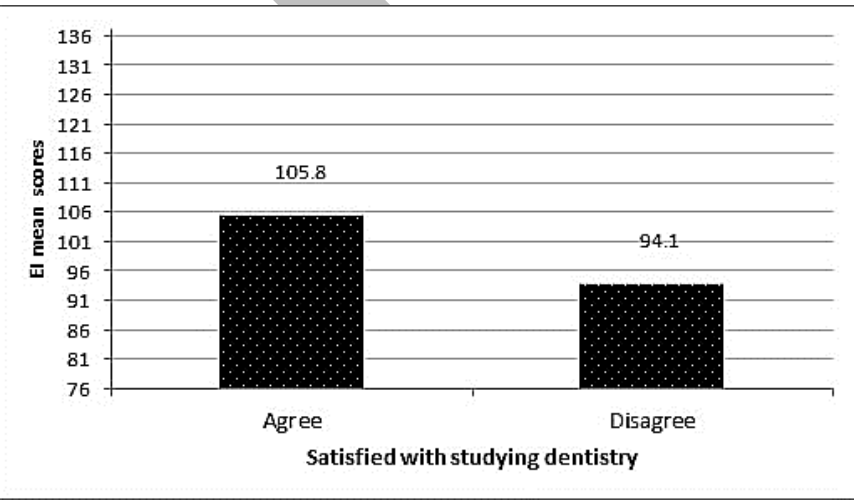

Figure 5: Total EI mean scores according to satisfaction with studying dentistry.

As a response to the question, if they wish to enroll in a post-graduate dental sub-specialty program, most of the respondents agreed, while only $7.1 \%$ of them did not (Table 1 ). When comparing levels of EI, the latter ones were found to have significantly lower EI levels $(98.4 \pm 11.7)$ (Fig 6). It could be concluded that the EI plays an important role in motivating dentists to enroll in post-graduate studies and enhance their careers.

Although the present study revealed some important findings and recommendations in the field of dentistry, certain limitations should be considered. The self-reported measures, generally, can be considered accurate only if an individual's self-concept is precise, they are prone to response biases for social desirability effects, which may result in exaggerated responses influencing the study results (35).

Therefore, it is recommended that Faculty of Dentistry should try to maintain and enhance the EI levels of its dental students specially females over the following years, while raising the awareness of the younger generations about the importance of these items to their effective performance. Workshops and seminars should be conducted for the dental staff to incorporate the concept of EI in their teaching methodology, in addition to knowing how to evaluate and enhance EI of their dental students. (36)

It is desirable for future researcher to examine the relation between student's EI and their academic achievement, moreover, longitudinal studies should be conducted to measure the differences between student's EI levels prior to 
entrance, across the different years of study and just before obtaining the bachelor degree, besides a comprehensive assessment of the curriculum contents should be made to check its role in improving students EI skills. It would, also, be useful to repeat this study with larger numbers and a variety of student groups, from different faculties to determine whether different professions in healthcare attract students with similar EI scores and if they differ from students of other faculties. Furthermore, studies are required to establish a valid and reliable measure of EI that is specifically designed for dental students at their study environment and settings.

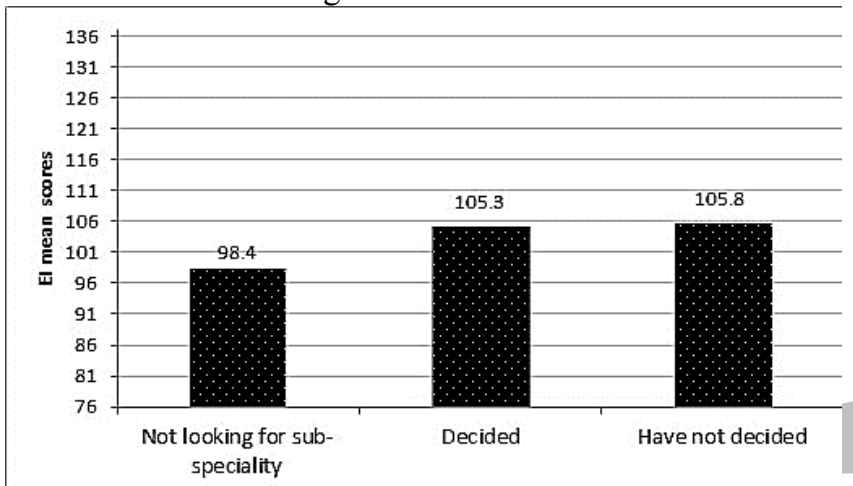

Figure 6: Total EI mean scores according to the desire to take a dental sub-specialty.

\section{CONCLUSIONS}

This is the first study in Egypt that explores EI levels in a sample of dentists. It was observed that High overall Emotional Intelligence is found in more than $84 \%$ of the participants. Significant differences in EI levels were found regarding gender, marital status, and study related characteristics, such as reason for choosing dentistry, satisfaction with study and desire to enroll in a dental postgraduate program. Hence this study provides primarily baseline data for the dental committee and spots the light over the importance of EI for dentists, further understanding of its relationships with academic and career needs should be explored, for achieving better dental quality and professional success.

\section{CONFLICT OF INTEREST}

The authors declared that they have no conflicts of interest.

\section{REFERENCES}

1. Goleman D. Working with emotional intelligence. New York: Bantam; 1998.

2. Salovey P, Mayer JD. Emotional intelligence. Imagination, cognition, and personality 1990; 9:185-211.

3. Goleman D. Emotional intelligence: why it can matter more than IQ. New York: Bantam; 1995.

4. Bar-On R. Emotional quotient inventory [Technical manual]. Toronto, Ontario, Canada: Multi-Health Systems; 2004.

5. Gignac GE. Genos Emotional Intelligence Inventory: Technical Manual. Sydney, Australia, Genos: Pty Ltd; 2008.

6. Stough C, Saklofske DH, Parker JDA. Assessing emotional intelligence: theory, research, and applications. NY, USA: Springer; 2009.

7. Montasem A, Brown SL, Harris R. Do core self-evaluations and trait emotional intelligence predict subjective well- being in dental students? J Appl Soc Psychol 2013; 43:1097-103.

8. Rivers SE, Brackett MA, Reyes MR, Mayer JD, Caruso DR, Salovey P. Measuring emotional intelligence in early adolescence with the MSCEIT-YV: Psychometric properties and relationship with academic performance and psychosocial functioning. J Psychoeduc Assess 2012; 30:344-66.

9. Ghoniem A, ElKhouly S, Mohsen G, Ibrahim M. Impact of Emotional Intelligence and Gender on Job Satisfaction among Egyptian Government Sector Employees. Curr Res J Soc Sci 2011; 3:22-7.

10. Weng HC, Chen HC, Chen HJ, Lu K, Hung SY. Doctors' emotional intelligence and the patient-doctor relationship. Med Educ 2008; 42:703-11.

11. Hannah A, Lim BT, Ayers KMS. Emotional intelligence and clinical interview performance of dental students. J Dent Educ 2009; 73:1107-17.

12. Hasegawa Y, Ninomiya K, Fujii K, Sekimoto T. Emotional intelligence score and performance of dental undergraduates. Odontology 2015. [Available from: http://link.springer.com/article/10.1007\%2Fs10266-0150219-0]

13. Azimi S, AsgharNejad Farid AA, Kharazi Fard MJ, Khoei N. Emotional intelligence of dental students and patient satisfaction. Eur J Dent Educ 2010; 14:129-32.

14. Pau A, Sabri BA. Relationship between emotional intelligence and job satisfaction in newly qualified Malaysian dentists. Asia Pac J Public Health 2015; 27:1733-41.

15. Pau AKH, Croucher R. Emotional intelligence and perceived stress in dental undergraduates. J Dent Educ 2003; 67:1023-8.

16. Pau A, Rowland ML, Naidoo S, AbdulKadir R, Makrynika E, Moraru R, et al. Emotional intelligence and perceived stress in dental undergraduates: A multinational survey. J Dent Educ 2007; 71:197-204.

17. Birks Y, McKendree J, Watt I. Emotional intelligence and perceived stress in healthcare students: a multi-institutional, multi-professional survey. BMC Med Educ 2009; 9:61. Available

from: http://bmcmededuc.biomedcentral.com/articles/10.1186/14 72-6920-9-61

18. Pau A, Croucher R, Sohanpal R, Muirhead V, Seymour K. Emotional intelligence and stress coping in dental undergraduates--a qualitative study. Br Dent J 2004; 197:205-9.

19. Grewal D, Davidson HA. Emotional intelligence and graduate medical education. JAMA 2008; 300:1200-2.

20. Arora S, Ashrafian H, Davis R, Athanasiou T, Darzi A, Sevdalis N. Emotional intelligence in medicine: a systematic review through the context of the ACGME competencies. Med Educ 2010; 44:749-64.

21. Syed A. Medical Schools and emotional intelligence screening. The York Scholar 2011; 8.1: 1-9.

22. Johnson DR. Emotional intelligence as a crucial component to medical education. Int J Med Educ 2015; 6:179-83.

23. Victoroff KZ, Boyatzis RE. What is the relationship between emotional intelligence and dental student clinical performance? J Dent Educ 2013; 77:416-26.

24. Bhaskar DJ, Aruna DS, Rajesh G, Suganna M, Suvarna M. Emotional intelligence of pedodontics and preventive dentistry postgraduate students in India. Eur J Dent Educ 2013; 17: e5-e9. 
25. Ravichandra KS, Ravi GR, Kandregula CR, Vundavalli S, Srikanth K, Lakhotia D. Emotional intelligence among dental undergraduate students: An indispensable and ignored aspect in dentistry. J Int Oral Health 2015; 7:69-72.

26. Mahmoud HM, Abd El-Dayem SM, Mousa MA. Emotional intelligence among Baccalaureate students at the Faculty of Nursing, Alexandria University, Egypt: A cross-sectional study. Journal of Education and Practice 2013; 4:49-61.

27. Ibrahim AF, Akel DT, Abd El Fatah LAM, Abudari MO. Emotional intelligence and internet addiction among nursing interns. Clinical Nursing Studies 2016; 4:70-80.

28. Gignac GE. Genos Emotional intelligence inventory: Questionnaires [cited: 9 August 2014] Available from: https://www.genosinternational.com/emotionalintelligence/for-researchers

29. Perera HN, DiGiacomo M. The relationship of trait emotional intelligence with academic performance: A metaanalytic review. Learn Individ Differ. 2013; 28:20-33

30. Atteya SM, Saleh SM, Abdelaziz WE. Attitudes of dental interns towards learning communication skills in Alexandria University and Pharos University (dissertation). Alexandria: Alexandria University; 2016.

31. Austin EJ, Evans P, Magnus B, O'Hanlon K. A preliminary study of empathy, emotional intelligence and examination performance in MBChB students. Med Educ 2007; 71:6849.

32. Carrothers RM, Gregory SW Jr, Gallagher TJ. Measuring emotional intelligence of medical school applicants. Acad Med 2000; 75:456-63.

33. Du Toit J, Jain S, Montalli V, Govender U. Dental students' motivations for their career choice: an international investigative report. J Dent Educ 2014; 78:605-13.

34. Peker I, Alkurt MT, Usta MG, Turkbay T. The evaluation of perceived sources of stress and stress levels among Turkish dental students. Int Dent J 2009; 59:103-11.

35. Perez JC, Petrides KV, Furnham A. Measuring emotional intelligence. In: Schulze R. Roberts RD, eds. Emotional Intelligence: An international Handbook. Ashland, OH, US: Hogrefe \& Huber Publishers; 2005. p.123-40.

36. Salovey P, Sluyter D. Emotional development and emotional intelligence: Implications for educators. New York: Basic Books; 1997.p.3-31. 